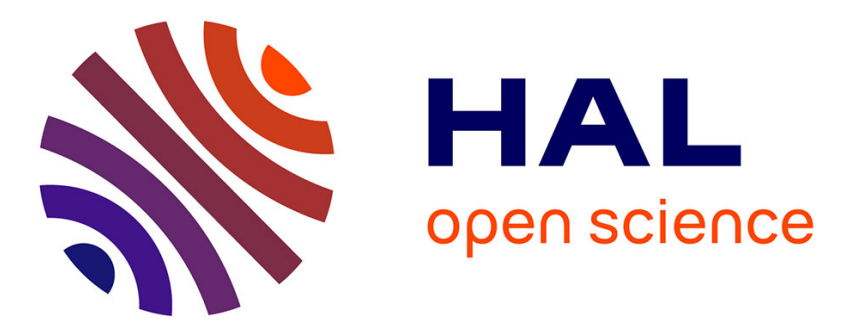

\title{
Observations of momentary liquefaction caused by breaking waves around a coastal structure
}

Mathieu Mory, Hervé Michallet, Stéphane Abadie, I. Piedra-Cueva, D. Bonjean, P. Breul, M. Cassen

\section{- To cite this version:}

Mathieu Mory, Hervé Michallet, Stéphane Abadie, I. Piedra-Cueva, D. Bonjean, et al.. Observations of momentary liquefaction caused by breaking waves around a coastal structure. 29th Conference on Coastal Engineering, Sep 2004, Lisbon, Portugal. 10.1142/9789812701916_0339 . hal-00260392

\section{HAL Id: hal-00260392 \\ https://hal.science/hal-00260392}

Submitted on 26 Apr 2020

HAL is a multi-disciplinary open access archive for the deposit and dissemination of scientific research documents, whether they are published or not. The documents may come from teaching and research institutions in France or abroad, or from public or private research centers.
L'archive ouverte pluridisciplinaire HAL, est destinée au dépôt et à la diffusion de documents scientifiques de niveau recherche, publiés ou non, émanant des établissements d'enseignement et de recherche français ou étrangers, des laboratoires publics ou privés. 


\title{
OBSERVATIONS OF MOMENTARY LIQUEFACTION CAUSED BY BREAKING WAVES AROUND A COASTAL STRUCTURE
}

\author{
MATHIEU MORY
}

ENSGTI, Université de Pau et des Pays de l'Adour, BP 7511, 64075 Pau, France

HERVE MICHALLET

LEGI (UJF-INPG-CNRS), BP 53, 38041 Grenoble Cédex, France

STEPHANE ABADIE

LaSAGeC, Université de Pau et des Pays de l'Adour,Parc Montaury, 64600 Anglet,

France

ISMAEL PIEDRA-CUEVA

ENSGTI, Université de Pau et des Pays de l'Adour, BP 7511, 64075 Pau, France

DAVID BONJEAN

Laboratoire 3S (UJF-INPG-CNRS), BP 53, 38041 Grenoble Cédex, France

PIERRE BREUL

LERMES-CUST, rue des Meuniers, BP206, 63174 Aubière Cédex, France

\section{MATHIEU CASSEN}

Imartec SARL, 282 chemin de Matoucas, 40600 Biscarosse, France

This paper aims at demonstrating the occurrence of momentary liquefaction in a sandy soil around a coastal structure subject to wave forcing. This was made in the field, using as coastal structure a bunker from the Second World War that is currently situated on the beach at Capbreton on the Atlantic coast of south-west France. By positioning pressure sensors at different levels inside the soil, time series of simultaneous pore pressure measurements were acquired while the position of the soil level was monitored. Analysis of the pressure measurements demonstrated that the sediment layer on top of the bed does not remain continuously in static equilibrium. An upward pressure gradient was sometimes observed, which could overcome the effective weight of the sediment. Pore pressure variations inside the soil were compared, using a Fourier analysis of the time series, with the theory put forward by Sakai et al. (1992) whereby the damping of pore pressure variations inside the soil can be quantified. A surprisingly good agreement is found when the gas content is adjusted in the model to $1 \%$. This indicates the existence of a significant amount of gas inside the soil. This property is confirmed in the field by geo-endoscopic videos. 


\section{Introduction}

The occurrence of momentary liquefaction of a sandy bed by water waves passing over the soil has been described theoretically by various authors, in particular Mei and Foda (1981) and Sakai et al. (1992). Equations describing the flow in the sandy bed when water gravity waves pass over it show that the variation in time and space of the pore pressure is damped with increasing depth and are subject to a phase shift as compared with variations at the bed surface. The two effects may lead to the occurrence of momentary liquefaction, but, for real flow and soil conditions, the phenomenon is highly sensitive to the presence of gas inside the soil (Gratiot and Mory 2000). To our knowledge, liquefaction produced by surface waves has not been observed in the field. This paper reports on a field experiment which aimed at observing liquefaction and scour around a coastal structure. The field experiment was carried out at Capbreton on the Atlantic coast in south-west France. This beach is subject to very strong wave forcing. A bunker from the Second World War which is now situated on the beach (due to the significant beach retreat observed there) was used as coastal structure. Due to its weight and size, the bunker is representative of coastal engineering structures. It is fully emerged at low tide and partially submerged at high tide. These conditions offer a reasonable opportunity to investigate also the gas content inside the soil during a tidal cycle.

Four field experiment trials were carried out in 2002 and 2003. Various wave conditions were achieved, ranging from calm to very rough waves. The experiments were carried out during high tide periods. Various instruments were fixed on the bunker that measured flow properties in the water layer, pressure variations inside the soil and bed level variations. Time series covering the part of the tidal period during which the soil is covered with water were recorded. The beach morphodynamics variations over successive tides were measured in the vicinity of the bunker using a GPS system and soil geotechnical properties were as well determined. Finally, the gas content inside the soil was investigated using an endoscopic video camera. Part of the results obtained are in the course of publication. The reader should refer to Mory et al. (2005) for a general description of the field experiment and to Bonjean et al. (2004) for an account of the geotechnical soil properties. We just mention here that the soil is made of sand $\left(d_{10}=220 \mu \mathrm{m}, d_{50}=350 \mu \mathrm{m}, d_{901}=500 \mu \mathrm{m}\right)$. In this short paper, we focus on the analysis of typical momentary liquefaction events and we demonstrate the importance of gas contained in the soil. 


\section{The field experiment setup}

The arrangement of measurement equipment, which was fixed on the bunker, is shown in Figure 1. For the data presented in this paper, liquefaction occurrence was investigated at a position in front of the bunker which is approximately in the middle of the wall facing the ocean. The main device is a vertical beam in which 5 pressure sensors (Druck PDCR 4030) and 8 fiber optics systems were implemented. The arrangement is sketched in Figure 2. The pressure sensors measure the pressure variations inside the soil and in the water layer at five different levels with an accuracy in water depth of about $0.3 \mathrm{~nm}$, whereas the 8 fiber optics systems allow to determine the position of the bed surface with regard to the position of pressure sensors. The vertical bar is inserted deeply inside the soil. The distance between two neighboring pressure sensors is $30 \mathrm{~cm}$. Each fiber optics sensor consists of two optical fibers set in parallel inside the steel bar, the fiber tips facing outside the bar. One of the fibers is the light emitter and the other receives the back-scattered light. The presence or absence of soil in front of the sensor is detected from the reflected light level. The principle of operation is described in more detail by Bonjean et al. (2004) which presents the typical response of an optical sensor during a calibration test.

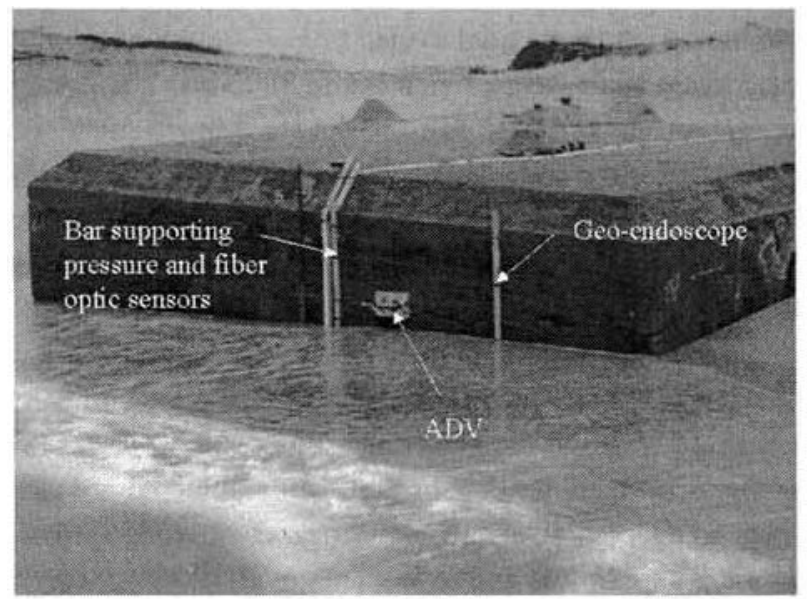

Figure 1. Photograph of the measurement eguipment fixed on the bunker wall facing the sea.

We do not comment here all measurement apparatus seen in Figure 1, because the complete set of data will not be discussed here, but we mention in particular a Nortek Vector Acoustic Doppler Velocimeter (ADV) in the water layer, and a vertical transparent plexiglas tube (diameter 14 nun) fixed on the bunker and extending inside the soil, in which an endoscopic camera can be introduced and displaced to visualize inside the soil the presence of gas and the 
displacement of sand particles. The technique of geoendoscopy was described by Breul, (1999). Soil depths ranging from 0 to $1.10 \mathrm{~m}$ below the soil surface were investigated.

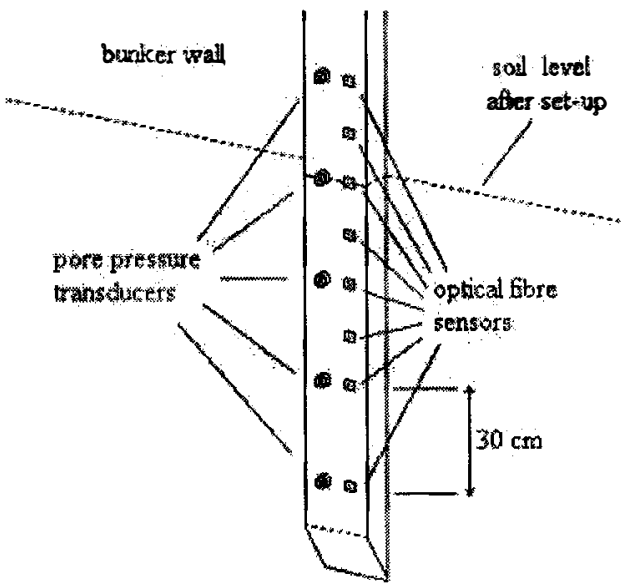

Figure 2. Implementation of pressure sensors and fiber optics probes in the bar.

During each tidal period, the complete set of data for liquefaction events detection consists of time series of pressure measurements, of bed level displacements at the position of the bar, and of velocity and pressure measured in the water layer by the ADV system. A conductivity system was also employed during the field experiment to measure bed level displacements, but the results are not discussed here. The system is described in another paper presented at the ICCE 2004 Conference (Cassen et al. 2004).

\section{Observations of momentary liquefaction in the sandy soil}

Figure $3 \mathrm{a}$ presents a time series of the absolute pore pressure measured simultaneously by the five pressure sensors. The significant wave height at the bunker for this record was about $1.10 \mathrm{~m}$ and the water depth $2.0 \mathrm{~m}$. The maximum pressure level is recorded by the lowest pressure sensor $\left(\mathrm{P}_{5}\right)$, while the minimum pressure level is recorded by the highest pressure sensor $P_{1}$. A detailed display of pore pressure variations inside the soil is given since the time series covers only a duration of about two wave periods. The three lowest sensors $\mathrm{P}_{3}$, $P_{4}$ and $P_{5}$ were inside the soil, as shown by bed level measurements (not presented here), whereas $P_{1}$ and $P_{2}$ were in the water layer or very close to the bed surface, respectively. Figure $3 \mathrm{a}$ displays clear damping of pressure variations with increasing distance inside the soil (from $P_{2}$ to $P_{5}$ ). The pressures are converted into water depth and the averaged pressure difference between two 
neighboring sensors is about $0.3 \mathrm{~m}$, which is the distance between two neighbouring sensors. Different behaviors are observed when considering the two wave periods in Figure 3a. During the first period, the sediment layer remains in static equilibrium since the pressure difference between two successive sensors remains approximately equal to $0.3 \mathrm{~m}$. During the second period a sudden and very rapid increase in the pressure measured by pressure sensors $P_{1}$ and $P_{2}$ is observed first. While the pressure increases later inside the soil, one observes a rapid and strong decrease in pressure at $P_{1}$ and $P_{2}$. The pressure difference $\Delta P_{3.2}=P_{3}-P_{2}$ is about $0.56 \mathrm{~m}$ for $t=5444 \mathrm{~s}$ (Figure $3 \mathrm{~b}$ ).
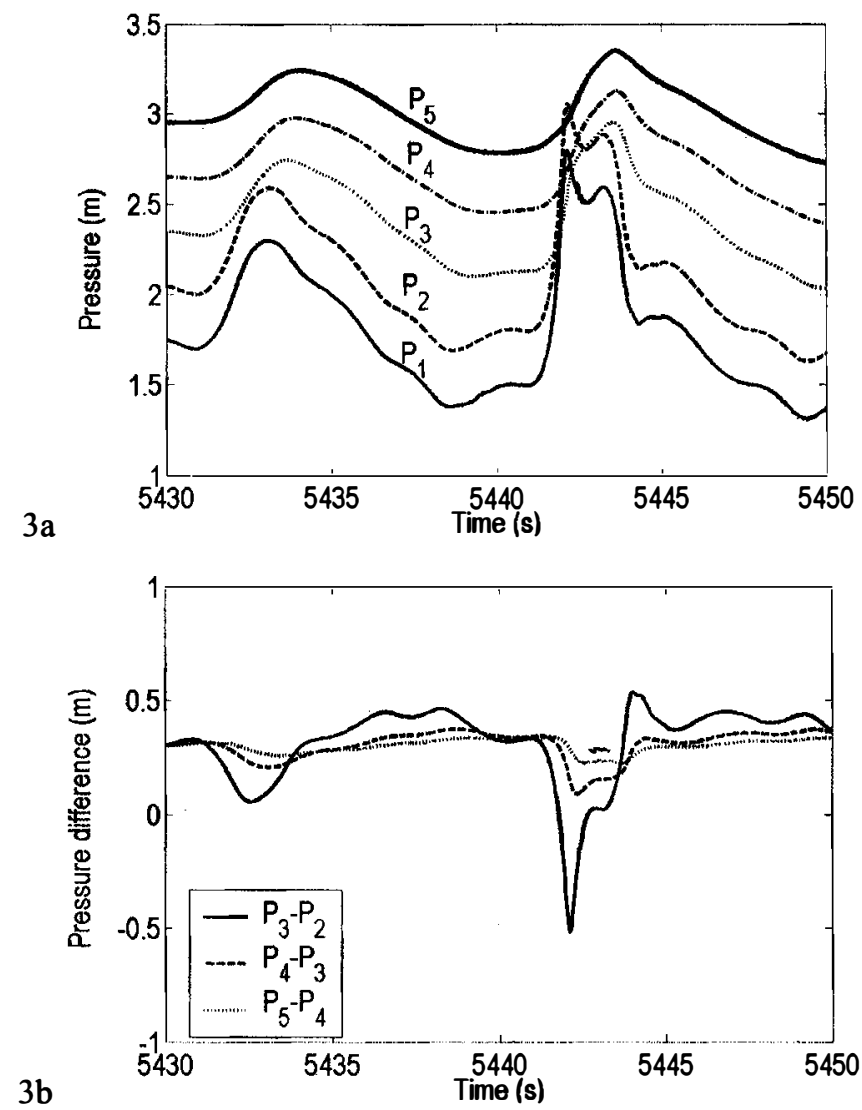

Figure 3. Typical time series of pressure measurements by the five pressure sensors implemented in the vertical bar.

When the pressure difference exceeds a certain positive value, it can overcome the effective weight of the sediment layer, which is no longer in static 
equilibrium. The critical pressure difference $\Delta P_{3.2}=P_{3}-P_{2}$ required to overcome the effective weight of the soil is

$$
\Delta P_{3.2}=P_{3}-P_{2}=\rho_{f} g h+\left(\rho_{s}-\rho_{f}\right)(1-\varepsilon) g h
$$

where $\rho_{s}$ and $\rho_{f}$ are the densities of sediment and water, respectively, $h$ the distance between the two sensors and $\varepsilon$ the porosity of the soil. Assuming a soil porosity $\varepsilon=0.5$, the critical upward pressure difference (converted into water depth) required to break the static equilibrium of the sediment layer contained between the two sensors is found to be $0.54 \mathrm{~m}$.

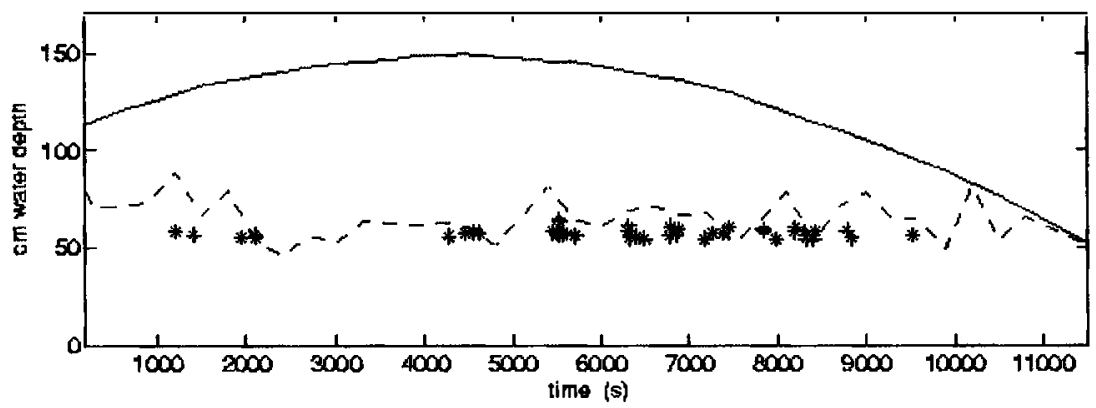

Figure 4. Statistics on liquefaction occurrence during a tidal cycle. ${ }^{*}$, maximum pressure $\Delta P_{3.2}$; solid line : mean water depth; dashed line : significant wave height.

Figure 4 presents a statistics of liquefaction events during the 2 hours $30 \mathrm{~min}$ of a tidal cycle. The maximum pressure difference $\Delta P_{3.2}$ between pressure sensor $P_{2}$ (around the bed surface) and pressure sensor $P_{3}\left(30 \mathrm{~cm}\right.$ below $\left.P_{2}\right)$, the mean water depth and the significant wave height are plotted for each liquefaction event observed. The critical value of $\Delta P_{3.2}$ required for liquefaction to occur was stated to be $0.54 \mathrm{~m}$. During the 2 hours $30 \mathrm{~min}$ considered, 47 liquefaction events were observed. The maximum pressure difference $\Delta P_{3.2}$ is usually less than $0.60 \mathrm{~m}$, presumably because liquefaction produces a dilated suspension in which the pore pressure rapidly decreases. Because the measured pressure difference $\Delta P_{3.2}$ is not significantly higher than the critical value of $0.54 \mathrm{~m}$, the effective occurrence of liquefaction may appear questionable, but we point out that this pressure difference is measured between two sensors located at a distance of $30 \mathrm{~cm}$ along a vertical in the soil. This is a significant depth of liquefied layer. We expect that more numerous liquefaction events involving a sediment layer less than $0.3 \mathrm{~m}$ thick did occur but they were not detected. 


\section{A Fourier analysis of pore pressure variations}

The damping of pore pressure variations inside the soil can be quantified using a Fourier analysis of pore pressure variations in time. The typical energy density spectra $S(f)$ of the pore water pressure measured by the 5 pressure sensors if shown in Figure 5. Three simply related frequencies are identified in the frequency spectra. The pressure decay inside the soil can be quantified as the ratio of the variance of the pressure spectral power density $P_{i}$ at a location $z_{i}$ below the seabed to the value at the bed surface determined from $P_{2}$. Since the two upper sensors $\mathbf{P}_{1}$ and $\mathbf{P}_{2}$ are in the water layer their power spectra are almost the same. The decay functions are plotted in Figure $6 a$ versus frequency. This indicates a strong and continuous decay of pore pressure variations with increasing depth in the $0.9 \mathrm{~m}$ layer of bed considered. The ratio of the pressure variance decreases*also with increasing frequency for the different depths considered.

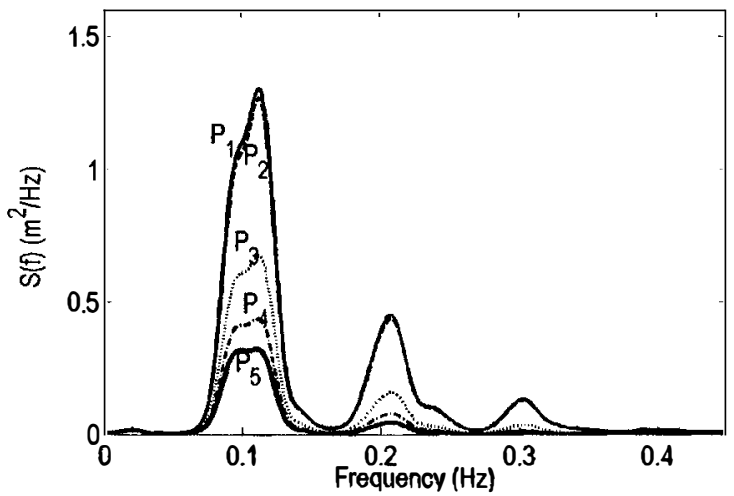

Figure 5. Energy power density spectra of pore pressure measurements made at five different levels.

Sakai, Hatanaka and Mase (1992) published a set of equations which describe the variation in time of pore pressure in the seabed when a monochromatic wave passes over an elastic plane sandy bed. The pore pressure variation inside the bed (eq. (3) from Sakai et al.) is written

$$
\frac{P(z)}{P o}=\left[\frac{1}{1+m} e^{-\lambda z}+\frac{m}{1+m} e^{\frac{(i-1) z}{\sqrt{2} \delta}}\right] e^{i(\lambda x-\sigma)}
$$

$\lambda$ and $\sigma$ are the wave number and frequency of the wave propagating in the water layer, respectively. The $z$ axis is oriented downward and $z=0$ is at the bed surface. The parameters appearing in (1) are defined as 
$m=\frac{n}{1-2 v} \frac{G}{\beta}, \beta=\frac{1}{\beta_{w}}+\frac{C_{\text {gas }}}{P_{\text {ref }}}$ and $\delta=\left(\frac{k}{\rho g} \frac{G}{\sigma}\right)^{1 / 2}\left[\frac{n G}{\beta}+\frac{1-2 v}{2(1-v)}\right]^{-1 / 2}$

The power density spectrum of pressure variations at the different depths considered is computed from eq. (1) in a straightforward way. For a bed porosity $n=0.50$, a bed permeability $k=2.010^{-4} \mathrm{~ms}^{-1}$, a shear modulus of the solid skeleton of the soil $G=210^{7} \mathrm{Nm}^{-2}$ and a Poisson modulus $v=0.498$ the gas content to $C_{g a s}$ was adjusted in order to obtain the best agreement of the plot in Figure $6 \mathrm{a}$ with the prediction of Sakaï model, which is shown in Figure $6 \mathrm{~b}$. This was obtained for $C_{g a s}=0.01$. Although the academic geometry of Sakaï et al. is different from ours, the comparison is surprisingly good. As such a gas content indicates a significant amount of gas in the soil, this comparison suggests that the gas contained in soil might effectively be an important parameter to consider.

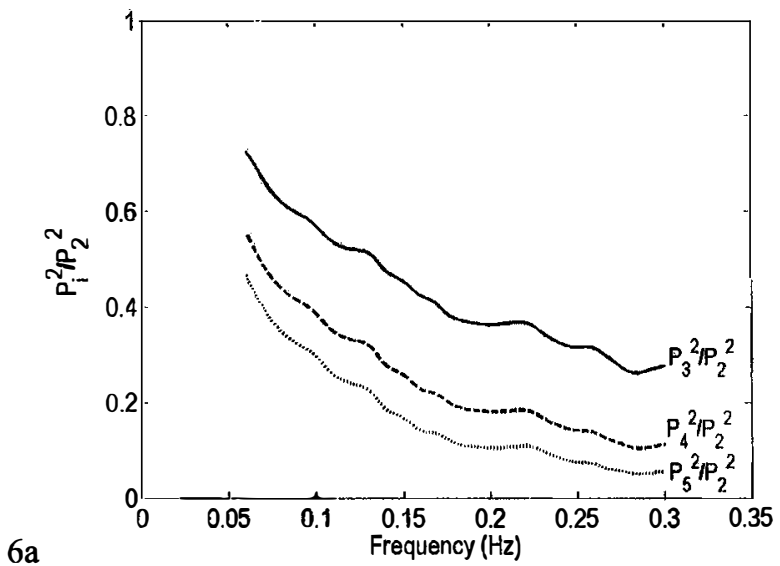

$6 \mathrm{~b}$

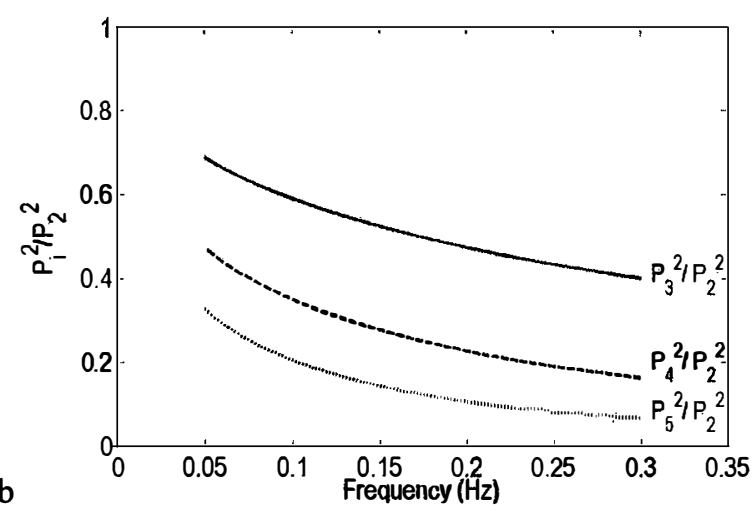

Figure 6. Ratio of pressure variance inside the bed layer (pressure sensors $P_{3}$ to $P_{5}$ ) to the pressure variance of pressure sensor $P_{2} .6 \mathrm{a}$ : Field data. $6 \mathrm{~b}$ : Prediction from Sakai et al.'s model. 


\section{Observations of gas inside the soil}

Video camera records were made with the endoscopic camera located at different depths inside the plexiglas tube. The video-endoscope provides images of a $25 \mathrm{~mm}^{2}$ plane section of the soil, in which sediment particles and bubbles are easily distinguished. An example is shown in Figure 7. On this photograph 3 large bubbles are identified. Recorded images were subjected to signal processing in order to analyze the soil automatically and extract information on the soil parameters (size of gas bubbles and particles, contact orientations, etc.). When the camera is placed sufficiently close below the soil surface, particles motions are also observed when waves impact on the bunker. The geoendoscope can also be used to determine the depth of the mobile layer. The reader should refer to Mory et al. (2005) for a general schematic of the geoendoscope system.

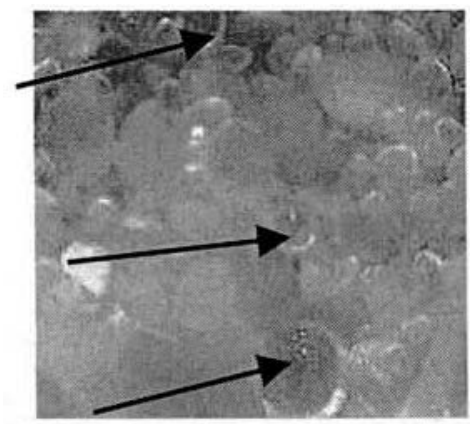

Figure 7. Endoscopic image inside the sosl. Arrows identify the position of bubbles.

The "surface gas content ratio", denoted $C_{s}$, was determined from image analysis. It is defined as the ratio of the area filled with gas bubbles to the total area of the image. A simple model was given by Mory et al. (2005) which express a relationship between the surface gas content ratio $C_{s}$ and the volume gas content $C_{v}$, defined as the volume of gas inside a volume of soil. Establishing this relationship requires that the depth of focus of video images inside the soil is known. Assuming that bubbles are spherical and that the depth of focus is the bubble diameter at a position where a bubble is found, the relationship $C_{r}=2 C_{s} / 3$ was deduced by Mory et al.

The geo-endoscope was used only during a few experiments because of limited availability. The wave climate was rather calm on these days. The geoendoscope found a significant amount gas in the sediment layer from $10 \mathrm{~cm}$ below the soil surface down to $50 \mathrm{~cm}$. Surface gas content value as high as $6 \%$ were determined. A thin sediment layer of about $0.10 \mathrm{~m}$ on top of the soil was found to be saturated with water. We interpret this feature by the mobility of 
sand particles near to the bed surface. This mobility helps the bubbles to escape from the soil, whereas the bubbles which were formed at low tide were partially captured deeper inside the soil. More deeper inside the soil the gas is again seen to vanish, presumably because no gas is introduced there at low tide.

Surface gas content as high as $6 \%$ is a significant level. It corresponds to a volume gas content in the range of a few percent. This order of magnitude is in agreement with the adjusted value obtained from the comparison of pressure variations measured inside the soil with Sakaï et al. (1992) model. We therefore obtain a strong indication that the gas content is a very important parameter for describing the processes inside the soil and the possible occurrence of liquefaction.

\section{Conclusion}

The results described in the paper were presented more like a summary, because most of them have been published or they are in the process of publication. In a complementary presentation, we tried here to stress the important conclusions of this study. The field experiments carried out at Capbreton aimed primarily at observing the occurrence of liquefaction in the vicinity of a coastal structure subject to wave forcing. To our knowledge, the phenomenon has not been observed before in the field. We did observe liquefaction. It was identified from pore pressure measurements inside the soil showing that the sediment layer on top of the soil does not remain in static equilibrium. No build-up of pore pressure is observed and the phenomenon is interpreted as momentary liquefaction.

The pore pressure measurement installation made it possible to quantify the damping of pore pressure variations with increasing distance inside the soil. A comparison was made using a Fourier analysis of the measured pressure variations with the prediction of Sakaï et al. model (1992). When the gas content is appropriately adjusted, a striking agreement of the decay of pressure variations with depth and with frequency is found between the model and our measurements. This suggests that gas content in the soil as high as a few percent are present in the sediment layer.

The presence of gas inside the soil was confirmed by geo-endoscopic videos. Bubbles were observed inside the soil and orders of magnitude of gas content of a few percent were confirmed. This indicates the very promising features of geoendoscopy for study liquefaction and more generally water flow and soil interactions. 


\section{Acknowledgments}

This study was partially funded by the European Commission Research Directorate, FP5, specific program "Energy, Environment and Sustainable Development", Contract No EVK3-CT-2000-00038, Liquefaction Around Marine Structures LIMAS. The authors thank J.P. Barbier for the design and construction of the fiber optics system. C. Carrère and JP Dufau are also acknowledged for having made possible the experimentation at Capbreton.

\section{References}

Bonjean, D., P. Foray, I. Piedra-Cueva, H. Michallet, P. Breul, Y. Haddani, M. Mory and S. Abadie. 2004. Monitoring of the foundations of a coastal structure submitted to breaking waves: occurrence of momentary liquefaction, Proc. $14^{\text {th }}$ ISOPE Conference, vol. II, 585-592, Toulon, France. Breul, P. 1999. Caractérisation endoscopique des milieux granulaires couplée à l'essai de pénétration, Thèse de docteur- ingénieur de l'Université de Clermont-Ferrand, pp280, Oct.1999.

Cassen, M., S. Abadie, G. Amaud and D. Morichon. 2004. A method based on electrical conductivity measurement to monitor local depth changes in the surf zone and in depth soil response to the wave action , $29^{\text {th }}$ ICCE Conference, Lisbon, Portugal.

Gratiot, N., and M. Mory. 2000. Wave induced sea bed liquefaction with application to mine burial, Proc. $10^{\text {th }}$ ISOPE Conference, Seattle, vol. II, 600-605, May 28-June 2.

Mei, C.C., and M.A. Foda. 1981. Wave induced responses in a fluid-filled poroelastic solid with a free surface - a boudary layer theory, Geophys. J. R. Astr. Soc., Vol 66, pp.597-631.

Mory, M., H. Michallet, D. Bonjean, I. Piedra-Cueva, J.M. Barnoud, P. Foray, S. Abadie and P. Breul 2005. A field study of momentary liquefaction and scour caused by waves around a coastal structure, accepted for publication in ASCE Journal of Waterway, Port, Coastal and Ocean Engineering.

Sakai T., K. Hatanaka and H. Mase 1992. Wave induced stresses in seabed and its momentary liquefaction, ASCE Journal of Waterway, Port, Coastal and Ocean Engineering, 118(WW2), 202-206. 